\title{
Preceitos e normas internas (kakun) de casas comerciais japonesas: um estudo sobre a longevidade e a ética da corporação japonesa
}

\section{Precepts and Internal Rules (Kakun) of Japanese Commercial Houses: A study about the longevity and ethics of the Japanese corporation}

Isao Yamamoto'

Sylvia Constant Vergara

\section{Resumo}

O estudo de corporações de uma das maiores economias mundiais se justifica em um mundo sem fronteiras no qual hoje vivemos e on de diferenças culturais afetam relações negociais. O objetivo é expliatar como as casas comerciais e outras corporações tradicionais japonesas conseguiram enorme longevidade. Fa privilegiado o papel desempenhado pelo kakun nessas corporações; au seja, o papel desempenhado por um conjunto de preceitos e normas internas que, tendo surgido nos séculos XVII e XVIII, tem viva a sua força até os dias correntes. O método escolhido para o estudo foi a historiografia, que visa ao resgate dos acontecimentos e das atividades humanas ao longo do tempo. Chegamos à conclusão de que muito do que pregava o kakun está hoje presente em estudos sobre organizações e gestão e que, associado a questões éticas, o kakun é, em grande parte, oresponsável pel a longevidade das em presas japonesas.

Pala vras-cha ve: longevidade; código deconduta; ética empresarial; visão a longo prazo.

\section{Abstract}

The present study about corporations from one the one of biggest world-wide economy is justified in a world without borders in which we live today and where cultura differences affect any business relations. This article aims to make clear how commerial and other traditional Japanese corporations have achieved great longevity. The role fulfilled by kakun in these corporations was highlighted, in other words, the role fulfilled by an internal set of precepts andrules that, having appeared in the 17th and 18th centuries, has firmly survived up to the current days. The method chosen for the study was the historiography, that aims for the redemption of the events and the human activities along the time. We come to the conclusion that a great deal of what kakun was advocating is present in studies on organizations and management and that kakun, associated with ethica issues, has been in great part responsible for the longevity of the Japanese enterprises.

Key words: longevity; code of conduct; business ethic; long-term vision.

\footnotetext{
Mestre emadministração de empresas pela PUC-Rio. Professor na Universidade Candido Mendes.Endereço: Rua Baronesa de Poconé, 152 Apto. 304 - Bloco 2 Lagoa - Rio de Janeiro/RJ - Brasil - CEP:22471270. E-mail: isao.rio@terra.com.br

2 Doutora em Educação pela UFRJ. Mestre em Administração Pública pela EBAP/FGV. Bacharel em Pedagogia pela UERJ. Professora da Escola Brasileira de Administração Pública e de Empresas da Fundaçao Getulio Vargas - EBAPE/FGV.Endereço: Praia de Botafogo, 190 - sala 533 - Botafogo - Rio de Janeiro/RJ Brasil - ๔EP: 22250-900. E-mail: sylvia.vergara@fgv.br

Artigo submetido em abril de 2008 e aceito em junho de 2008
} 


\section{Introdução}

Segundo o Sebrae (2004), no Brasil, 49,9\% das pequenas e médias empresas deixam de existir antes que completem dois anos de existência, 56,4\% antes de três anos e 59,9\% antes de quatro anos. Os motivos apontados pelos ex-proprietários são vários: falta de capital de giro, alta carga tributária, falta de clientes, má localização da empresa e outros. Esses dados remetem à questão da morte prematura de empresas. Todavia, tal morte não é desejada; ao contrário, o que proprietários desejam é que empresas tenham vida longa, seja em suas mãos, seja em mãos de outros que a adquiram. O tempo de vida de uma empresa é, portanto, tema relevante. Aqui, busca-se discutir otema da longevidade em outro cenário: o das empresas japonesas.

Além da questão da longevidade apontada pelo Sebrae, a literatura sobre administração revela que tem crescido o número de estudos acerca de espiritualidade nas organizações (ex: REGO et al, 2005). Eles têm apontado a ética como um dos bens intangíveis da empresa. Admite-se que empresas éticas têm maior probabilidade de contar com pessoas comprometidas. Este artigo discute a ética em empresas japonesas, associando-a à questão da longevidade.

Going concern é o conceito normalmente aceito como premissa básica de empresas no mundo ocidental, mas considera-se que ele pode ser válido também para o mundo oriental. Um exemplo pertinente é a empresa japonesa. Afinal, como as casas comerciais e outras corporações tradicionais japonesas conseguiram tamanha longevidade? Há algo em comum entre elas? Certamente, analisar um conjunto de fatores que contribuíram para essa longevidade nos levaria à questão central do significado de going concem e à razão de ser das corporações. O tema, complexo e amplo, tem merecido diversos ensaios e pesquisas empíricas no mundo acadêmico. Este artigo busca contribuir para enriquecer essa discussão, trazendo para ela o papel desempenhado pelo kakun dessas centenárias empresas do Japão. № mundo globalizado em que vivemos, analisar diferentes culturas parece pertinente, uma vez que pode nos ajudar, por exemplo, nas relações comerciais. O método escolhido foi a historiografia, que visa resgatar acontecimentos humanos ao longo do tempo, desvendando seu processo (CURADO, 2001; VERGARA, 2006).

A partir desta introdução, o artigo está dividido em cinco seções, seguidas da conclusão. A primeira seção traça um panorama das empresas japonesas com tradição secular e apresenta o instrumento chamado kakun. A segunda seção aborda o ambiente histórico-social que levava a classe de novos comerciantes da era Edo (16031868) a deixar o kakun da família como legado às gerações posteriores, analisando o significado desse instrumento. Também são analisados os principais ensinamentos do confucionismo e do budismo, além das formulações de alguns pensadores influentes daquela época, nitidamente refletidas no kakun. A terceira seção revela como funcionava uma casa comercial daquele período - tomando a organização de Echigo-Ya como exemplo típico -, além do sistema de carreira do comerciante. A quarta seção apresenta diversos exemplos de kakun - elaborados em sua maioria nos séculos XVII e XVIII - identificando a base do seu pensamento, as idéias comuns e o sistema de valores da classe de novos comerciantes daquele período. A quinta seção analisa 0 kakun do ponto de vista da longevidade da empresa japonesa, seguindo-se, então, as conclusões.

\section{A longevidade de empresas japonesas}

A empresa mais antiga do mundo é a Kongo Gumi, construtora especializada em templos budistas e xintoístas, conforme ratificou a revista inglesa The Econom ist (NOMURA, 2006). A construtora nasceu no ano 578, como uma cooperativa de carpinteiros artesãos que imigraram da Kudara, antiga Coréia. No segundo semestre de 2006, os principais jornais japoneses informaram sobre a crise financeira que a empresa atravessava e a iminente falência. Ent retanto, outra construtora criou uma nova empresa, abrigando todos os ex-empregados da Kongo Gumi, além de conseguir a transferência da razão social, motivo pelo qual o nome da empresa foi salvo (FUNABASHI, 2003; NOMURA, 2006).

A NHK, emissora japonesa de TV, em reportagem de junho de 2007 sobre a longevidade de empresas japonesas, mostrou que no Japão há um número superior a 3.000 empresas com mais de 200 anos de existência. Nas mesmas condições, a Alemanha possui 800 empresas, a Holanda, 200, os EUA, 14, a China, 9 e a Índia, 7, 
entre outros exemplos. Com mais de 100 anos de história, há cerca de 15.207 empresas japonesas, conforme revela a pesquisa realizada por Nomura (2006). O autor diz que, se forem incluídas empresas familiares e de pequeno porte, o número de empresas japonesas com mais de 100 anos de vida pode ultrapassar 100.000.

Funabashi (2003) mostra a convivência harmoniosa de empresas centenárias com a moderna paisagem de Tóquio. Segundo ele, a sede da Kokubu, empresa de produtos alimentícios fundada em 1712, fica no pequeno bairro de Nihonbashi, centro comercial de Tóquio. Em frente ao prédio da Kokubu situa-se Kuroe-Ya, empresa de produtos laqueados fundada em 1689. A empresa que fica ao seu lado é a Nishikawa-Sangyō, que começou em 1566 e que vende, desde então, almofadas e colchões tradicionais. A Shiroki-Ya, cuja origem remonta ao século XVII, hoje chamada Tokyu-Hyakkaten, é uma grande rede de lojas de departamentos que também fica perto da Kokubu. Em frente à Tokyu fica a Haibara, papelaria cuja fundação é datada de 1806. A YamamotoYama, empresa que vende algas marinhas secas e chá verde, começou suas atividades comerciais em 1690. Além dessas empresas, no mesmo bairro, há diversas outras igualmente tradicionais, como a Yagicho, fundada em 1737 e que comercializa produtos marinhos. A Mitsukoshi - que, com o nome de Echigo-Ya, nos idos de 1737, vendia vestidos e tecidos - é hoje uma rede de lojas de departamentos, a quarta colocada em termos de fat uramento. A Kiya, fundada em 1792, é especializada na fabricação e na comercialização de facas da cozinha. A Ninben, fundada em 1699, começou vendendo bonitos (um tipo de peixe) desidratados. A Murata, fundada em 1615, comercializava, na época, espelhos e, hoje, é uma ótica. Essas empresas continuam com vigor ainda hoje, superando inúmeras crises em sua longa trajetória de sucesso empresarial. Qual o papel nelas desempenhado pelo kakun?

O kakun é um conjunto de preceitos e princípios de conduta, elaborado e deixado por proprietários de casas comerciais e de artesãos a seus descendentes e empregados. É possível afirmar, com certa segurança, que a maioria das empresas japonesas com longa tradição segue esse tipo de código de conduta ou algo semelhante, herdado e mantido por sucessivas gerações ao longo de séculos. Num kakun destaca-se, aqui, o lado social, base ética das atividades empresariais e força motriz para a longevidade dos negócios. A longevidade era, em muitos casos, do próprio interesse (ou mesmo um objetivo) do kakun, tendo sido fundamental para a classe de comerciantes (NISHIYAMA et al, 1995; YAMAMOTO, 2005).

\section{A base ética da classe de comerciantes}

O cenário que este artigo aborda é a era $E d o(1603$ - 1868) no Japão. O regime sóciopolítico de então era o feudalismo. O poder centralizador era representado pelo xogunato Tokugawa. Cerca de 300 senhores feudais, subordinados diretamente ao Xogum, chefe militar supremo, serviam ao regime Tokugawa, o qual usava o confucionismo como instrumento de apoio moral e ético.

No início da era $E d o$, alguns comerciantes com privilégios e favorecimentos concedidos pelo próprio xogunato, enriqueceram graças aos negócios monopolistas ou oligopolistas. Entretanto, a maioria desses comerciantes quebrou e, portanto, seus negócios não tiveram continuidade. As freqüentes mudanças na política e a perda do poder econômico do próprio governo Tokugawa tomavam a situação dos novos ricos ainda mais instável, situação agravada pela inexistência da definição de missão empresarial. Assim, empresários deixaram seus nomes na história do Japão, apenas, como afortunados momentâneos (MINAMOT O, 1993; OISHI, 1995).

Na segunda metade do século XVII surgiu, porém, uma nova geração de comerciantes diante da maior oferta de mercadorias e do desenvolvimento de grandes mercadbs de consumo no Japão. Diferentemente daqueles comerciantes privilegiados e protegidos pelo xogunato Tokugawa do início do século XVII, os novos comerciantes concentraram sua at enção no crescente mercado de consumo e na logística entre produtores rurais e consumidores das cidades. Eles não contavam com nenhum favorecimento por parte do govemo. Ao contrário, o governo desprezava a classe e tornava mais difíceis suas condições de trabalho. O fato importante é que os consumidores da classe popular tornaram-se seus clientes. Os comerciantes contavam com sua própria sagacidade e agiam de acordo com o espírito do capitalismo, embora, bastante incipiente (MINAMOT O, 1993; OISHI, 1995). 
O maior interesse desses novos comerciantes era deixar o negócio da família para seus descendentes. Família deve ser entendida aqui em seu sentido mais amplo, abraçando não somente a família original, como também suas ramificações. O negócio da família não era simples ocupação, era status social. Na era $E d o$, perder o negócio da família significava perder espaço dentro da sociedade. Nos escritos deixados em forma de kakun pelos comerciantes daquela época - muitas vezes, autodenominados de constituição da família ou de regras internas da casa -, estavam resumidas as esperanças e as vontades dos pioneiros sobre o futuro do negócio e da família. Os escritos também revelavam as lições amargas aprendidas por eles nos momentos de crise e de adversidades ( NISHIYAMA et al, 1995; YAMAMOT O, 2005).

Deixar alguma coisa escrita, repleta de ensinamentos aos sucessores ou descendentes da família, era um ato bastante comum entre os nobres e os samurais, desde o século VIII. Quase sempre, esses escritos eram elaborados em situações de crise que abalavam a continuidade da família. Tanto samurais quanto comerciantes tinham o mesmo objetivo: a continuidade da família. Os senhores feudais importantes da era das grandes batalhas e conturbações sociais (séculos XV e XVI), deixaram um conjunto de normas e lições, com a esperança de que seus sucessores mantivessem o nome da família, observando as normas ao pé da letra (YAMAMOT O, 2005).

No final do século XVI, Genzaemon Gamo, de uma tradicional família de senhores feudais, deixou um recado com cinco parágrafos, destinado aos seus descendentes. Kuwata (2003) transcreveu esse registro, a partir do documento histórico da família, chamado Gamo-ke keizu yuishogaki (Apontamentos Históricos da Árvore Genealógica da Família Gamo), cuja data não se sabe ao certo. Ei-lo:

1. quem nasce numa família de samurai deve praticar, dia e noite, as artes da espada, do arco e flecha, da equitação e aprofundar estudos da arte da guerra.Porém, não basta fazê-lo superficialmente;

2. os samurais de hoje se esquecem de sua missão divina e vivem com ostentação e arrogância. Não cuidam bem de seus armamentos e de seus instrumentos de equitação. Desperdiçam dinheiro em coisas fút eis como a cerimônia de chá, o que é inútil e deve ser evitado;

3. não se esqueçam da fidelidade que devem ter com os seus superiores e da obediência e deveres com os seus pais. É indispensável at ender com piedade aos seus criados. Ser superior ou ser subordinado é algo predeterminado pelo destino do céu. Aceite-o com naturalidade;

4. se algum membro da família se arruinar, ajude-o com um décimo de sua riqueza;

5. saiba sua posição e seus limites e se mantenha rigorosamente neles.

6. Ao finalizar, desejo que meus descendentes observem esses cinco parágrafos com rigor.

Nesse kakun da família Gamo, é possível notar uma forte influência do budismo, o que era muito comum nos escritos deixados pelas famílias da classe samurai da época. Isto é, ser senhor ou ser subordinado (ou ser qualquer outra coisa) é apenas uma questão de arranjo divino do céu, cabendo a cada um aceitar seupapel com a maior naturalidade, vivendo com discrição, na sua posição, e sendo piedoso com as pessoas hierarquicamente inferiores que o cercam.

Essa manifestação era típica da classe samurai, que visava manter-se com simplicidade, mas com objetividade, de acordo com o papel da sua classe. Por outro lado, o estado ideal de relacionamento entre superiores e inferiores e entre pais e filhos foi um reflexo típico do ensinamento do confucionismo (KUWAT A, 2003).

Foi assim que os comerciantes encontraram em Shousan Suzuki (1579-1655) a defesa e o reconhecimento da importância da classe de comerciantes na sociedade. Diferentemente da classe de agricultores, a de comerciantes não produzia com suas próprias mãos. Esse fato não thes fazia merecer admiração ou respeito da sociedade da época, devido à influência das religiões da Idade Média, tanto na Europa quanto no Japão (MINAMOTO, 1993). A aceitação da classe de comerciantes era justificada apenas pela necessidade de sobrevivência. A maioria dos confucionistas aceitava a corrente de pensamento segundo a qual se deve "venerar produt ores rurais e desprezar comerciantes." Suzuki contra-argumentava dizendo: "Se há pessoas que estão precisando de determinado produto num lugar remoto, levar esse produto para elas equivale à providência 
do Buda. Por isso, os caixeiros viajantes que levam mercadorias para regiões remotas em benefício dos consumidores são represent antes do Buda.” (MINAMOT O, 1993).

Sekian Miyake (1665-1730), por seu turno, fundou em Osaka uma escola aberta do confucionismo (Kaitokudo), para os comerciantes. Ele ensinava as doutrinas e ensinamentos do confucionismo intimamente ligados ao dia-a-dia das pessoas, modificando-os em defesa da classe de comerciantes. Miyake dizia que o trabalho do comerciante era um caminho santo, já que melhorava a vida das pessoas, e que o dinheiro ganho com ele poderia servir para obras de beneficência, socorrendb muitos dos necessitados. Ao mesmo tempo, pedia aos alunos paciência para acatar o sistema hierárquico injusto e autocontrole para manter uma vida modesta, sem ost ent ação (TAKEMIT SU, 2003). O pensamento de Miyake foi desenvolvido e aprimorado mais tarde por Baigan Ishida (1685-1744).

Na hierarquia japonesa, os samurais vinham em primeiro lugar, os agricultores em segundo, os artesãos em terceiro e, por último, os comerciantes. A exemplo das famílias da classe samurai, os comerciantes começaram a elaborar seus kakuns (ou códigos de conduta da família) a partir do início do século XVII. Mais tarde, quando o xogunato se sentiu ameaçado com o avanço do poder econômico da classe de comerciantes, uma série de medidas de arrocho contra esta classe foi tomada. Em casos extremos, alguns comerciantes de sucesso foram presos e severamente punidos, simplesmente, por terem exibido ostentação em suas moradias, alimentação ou trajes. Que fazer? Mesmo detentores de riqueza, os comerciantes não conseguiram apresentar uma altemativa à submissão ao regime hierárquico criado pelo xogunato Tokugawa. Daí resultou o esforço para identificar a razão de ser da classe comerciante e de viver com certa dignidade baseada na frugalidade, no trabalho árduo e no talento individual como comerciante (MINAMOTO, 1993; YAMAMOTO, 2005). Eis aí uma estratégia de sobrevivência.

Inferiorizada na sociedade e vendo menosprezado o seu próprio ato de intermediação de compra e venda de mercadorias, a nova classe de comerciantes encontrou nos pensamentos de Ishida, fundador da escola de pensamento chamado Shingaku, o amparo ético e a justificativa de suas at ividades comerciais. Ishida nasceu numa família de agricultores e, aos 11 anos, foi deixado em Kioto aos cuidados de uma casa comercial, como era costume naquela época. Quando Ishida tinha 15 anos, o estabelecimento comercial onde trabalhava foi à falência e ele retomou à sua terra natal, vivendo como lavrador até os 23 anos de idade. Foi quando voltou a trabalhar em outra casa comercial, mas já sabendo que não teria condições de ser um comerciante, por ter ficado fora do sistema. Aos 43 anos, encontrou o mestre Ryoun Oguri, renomado confucionista, que o iniciou como pensador. Por ter sido criado no campo e na cidade, Ishida tornou-se um pensador prático que, por sua perspicácia, buscou resposta para os problemas essenciais do ser humano (MINAMOTO, 1993).

O pensamento pragmático de Ishida se baseou num misto de budismo, confucionismo, taoísmo e xintoísmo. Segundo ele, tanto a classe de samurais quanto a de comerciantes, tem sua função divina e seu próprio caminho. Ishida considerava que apesar da hierarquia social, os homens são iguais, independente do seu trabalho, e criticava severamente o desprezo que os samurais dispensavam aos comerciantes. Quanto ao lucro, ele o aceitava como algo natural, como o caminho divino dos comerciantes, ainda que o condenasse quando excessivo ou auferido de forma desonesta. Nesse sentido, via a honestidade como a base da ética humana, considerando-a premissa fundamental para a atividade comercial (NIMAMOTO, 1993).

O desprestígio da classe de comerciantes em oposição à grande respeitabilidade então usufruída pelos produt ores rurais que, como dito, também ocorria na Europa, relacionava-se à questão do próprio ato de ganhar dinheiro ou de buscar lucros, da classe de comerciantes. Veja-se que este não era um posicionamento novo. Tanto Aristóteles (384-322 a.C.) quanto Platão (428-347 a.C.) tinham posição crítica a respeito. Aristóteles, por exemplo, considerava nat ural a troca ou compra e venda de mercadorias para suprir necessidades. Contudo, as transações visando ao lucro em si eram vistas como contrárias à justiça. A moeda, para ele, não deveria passar de simples meio de troca e, portanto, não deveria ser o próprio objetivo. Emprestar dinheiro para ganhar juros, nem entraria em sua cogit ação (T AKEUCHI, 1994).

Afinal, os comerciantes podem ganhar dinheiro? Eles compram barato e vendem caro. O que justifica esse comportamento? Tomás de Aquino (1225-1274), teólogo católico e filósofo da Idade Medieval, admitia o 
comércio entre regiões remotas, contanto que o lucro auferido na transação fosse razoável e correspondesse aos esforços envolvidos no negócio. Para ele, o lucro justo proveniente da transação realizada no mercado competitivo, sem ilicitude e monopólio, era aceitável (T AKEUCHI, 1994).

No que conceme à história japonesa, além de Suzuki, Miyake e Ishida, havia outros pensadores importantes, como Doji Nakazawa (1725-1803) e Seiryou Kaiho (1755-1817), que contribuíram para a formação da base ética da classe dos comerciantes da época e, de certa forma, do Japão de hoje (KOJIMA, 1989)

\section{A família Mitsui e seus ensinamentos}

É fácil imaginar que as corporações japonesas da época não tinham a forma organizacional nem jurídica do padrão ocidental de empresa moderna. Segundo Takamura (1996), as primeiras empresas japonesas de sociedade anônima compatível com as ocidentais do mesmo padrão jurídico foram os bancos estatais criados por decreto em 1872. Sua proliferação aconteceu em torno de 1900. Takamura reconhece que existe uma lacuna muito grande entre as corporações da época Edo (1603-1868) e as empresas criadas na era Meiji (18681911), porém sugere que as corporações antigas já tinham algumas precondições facilitadoras de sua transformação em organizações modernas. $\mathrm{O}$ autor afirma que nas corporações familiares de grande porte da era $E d o$ (Echigo-Ya, por exemplo, empregava entre 300 e 400 empregados, somente na loja de Tóquio), a divisão entre a propriedade e a gestão do negócio era aceita com naturalidade, o que, certamente, facilitava a aceitação de cargo de gerente por pessoa sem parentesco com a família proprietária. Essa separação entre a propriedade e a gestão é, certamente, uma das características das organizações modernas. Hoje, pesquisadores japoneses e de outros países são unânimes em admitir que as casas comerciais japonesas surgidas a partir do século XVII representam a forma inicial de empresas por cotas ou sociedade limitada da era moderna.

A família Mitsui, origem de um dos maiores grupos econômicos formados nos séculos XIX e XX que, na época anterior, at uava nas at ividades de comércio, câmbio e financeiras (a já citada Mitsukoshi pertencia a essa família) chegou a ter uma organização complexa espalhada pelo Japão já no século XVII, com suas at ividades bastante diversificadas. O controle e a avaliação de empregados eram rígidos, e quem não at endia aos requisitos comportamentais e profissionais preestabelecidos pela casa era demitido sumariamente. Até os proprietários e sucessores, quando ficavam fora da linha de conduta, eram destituídos havendo consenso quanto a isso entre os demais membros executivos. As finanças da família Mitsui e as do negócio eram rigorosamente separadas e ninguém tinha livre acesso a grandes somas de dinheiro. Nas casas comerciais existia a gestão por competência e por resultado, o que não acontecia com as casas tradicionais da classe samurai. Estas procuravam apenas a continuidade da família por consangüinidade; a sucessão era praticamente automática e garantida pelos senhores feudais. Por outro lado, as casas comerciais empregavam, com freqüência, pessoas de fora da família como gestores do negócio. O critério para admissão era o conhecimento técnico e as virtudes pessoais. A família Mitsui, composta de uma família principal da linhagem e mais 10 famílias ramificadas, mantinha 220 cotas de participação do negócio entre elas e a distribuição do lucro era feita conforme o número de cotas que cada cotista possuía (YASUOKA, 1993).

Existia um bem definido plano de carreira dos empregados nas casas comerciais e este foi colocado em prática durante séculos. Não havia tratamento especial, nem privilégio em favor dos membros da família Mitsui pelo critério de parentesco. O que pesava era a capacidade e o desempenho do indivíduo, acompanhado do resultado dos que participavam do negócio. Havia três cargos na casa comercial japonesa típica: decchi, tedai e banto. Decchi era o cargo inferior (seria um correspondente a boy). Meninos de, aproximadamente, 10 anos, depois de passarem pela terakoya (um tipo de escola primária privada da época, onde se ensinava a ler e a escrever, além da matemática básica e do manuseio do ábaco), começavam a trabalhar como decchi, fazendo serviços intemos e extemos de menor importância. Eles viviam dentro do estabelecimento comercial, sem remuneração. Os meninos tinham a obrigação de adquirir conhecimentos e experiência, de modo que pudessem ser bons comerciantes. As casas comerciais tinham obrigação de sustentar e criar esses meninos, transformando-os em dedicados e talentosos comerciantes. Depois de 10 anos de serviço como decchi, os rapazes começavam a at ender diretamente os clientes da loja, como tedai. 
Tedai eram os vendedores e atendentes de hoje. Realizavam, também, serviços de compra de mercadorias, transporte, contabilidade e de finanças. Se o chefe da unidade ou da matriz reconhecesse o talento e o empenho do tedai como bom e fiel empregado, depois da dedicação de outros 10 anos ele era promovido a banto, o cargo mais prestigiado numa casa comercial. O banto participava da gestão da unidade ou da matriz junto com os chefões da família-clã. Eram os gerentes de hoje. O banto (e parte dos tedais) tinha o direito de manter uma casa própria; portanto, de ter família e de trabalhar no estabelecimento. Quando a confiança do chefe da família-clã era grande, o banto recebia todo o apoio logístico e financeiro para abrir um novo estabelecimento comercial próprio. Nesse caso, tinha que escolher o local do estabelecimento em outros bairros ou cidades. Se ficasse no mesmo bairro, tinha que ter um negócio um pouco diferente do da matriz, para evitar a concorrência direta. Entretanto, havia diversos casos em que a abertura de novos estabelecimentos sob nova direção tinha como objetivo incrementar o negócio global do grupo. É possível afirmar que essas casas comerciais já tinham o perfil de empresas de grande porte da era moderna (NISHIYAMA et al, 1995; OGI et al, 1997).

É interessante que muitas empresas japonesas que sobreviveram centenas de anos mantenham, ainda hoje, seu próprio código de conduta ou o conjunto de preceitos e normas intemas da família: seu kakun. Ele é considerado ora como lema da corporação, ora como talismã na hora da adversidade. "Mantenha-se no negócio principal da casa e não faça diversificação leviana”; “O melhor negócio é aquele que proporciona lucro para todas as partes interessadas: os clientes, a comunidade e a nossa casa"; "O dinheiro ganho sem suor é o dinheiro que se perde rapidamente”; "P rática de virtudes e boas condutas às ocultas são louváveis e incentivadas”; "Dê sua contribuição à sociedade onde vivemos. Somos parte dela” (SUENAGA, 2000; YAMAMOTO, 2005). Essas palavras são alguns exemplos observados com freqüência nesses escritos históricos das casas comerciais japonesas, elaborados nos séculos XVII e XVIII. Há nelas influências inegáveis do budismo, do confucionismo, do taoísmo e do pensamento representado por Baigan Ishida, já mencionado.

Takatoshi Mitsui (1622-1694), considerado o fundador efetivo da família Mitsui, revolucionou a forma de fazer negócios no Japão. Na época, os comerciantes de grande porte não vendiam suas mercadorias em suas lojas de modo direto aos clientes. Os negócios chamados de "misemono akinai" ou "yashikiuri” eram comuns. Os comerciantes levavam grandes quantidades de suas mercadorias às casas de grandes clientes e as vendiam a crédito. A cobrança ocorria apenas uma vez no fim do ano ou, no máximo, uma vez a cada semestre. Por isso, para evitar problemas de caixa, os comerciantes embutiam juros altos no seu preço. Essa maneira de fazer negócio (vendas indiretas a crédito com juros altos) foi abolida pela família Mitsui, que começou a vender suas mercadorias de modo direto, expondo-as na loja e a preços à vista, sem juros e accessíveis a todos. Isso surpreendeu os demais comerciantes e foi considerado uma revolução na época. Foi Takatoshi quem fundou a mencionada loja Echigo-Ya em Tóquio (1673), na era $E d o$. Essa forma de vendas agradou aos pequenos, porém numerosos consumidores da cidade de $E d o$, e o nome de Echigo-Ya tornou-se ícone das novidades da época. Echigo-Ya foi, também, pioneira no atacado. Começou a vender grande quantidade de mercadorias aos varejistas do país inteiro. Vendia por preço baixo e ganhava na quantidade.

Um pouco antes da sua morte, Takatoshi Mitsui deixou um conjunto do que foram suas últimas palavras e ensinamentos aos seus descendentes (YAMAMOT O, 2005). Veja-se:

- uma árvore solitária é fácil de quebrar. Árvores juntas são mais fortes. Todos os membros da família devem se unir para fortalecer os negócios da família;

- nada de ostentação e luxo. Fazer economia e viver com frugalidade é o que importa;

- procure e promova os novos talentos, mas sem causar inveja ou descontentamento aos empregados veteranos;

- filhos com parentesco da própria família Mitsui devem ser tratados como um criado qualquer e treinados sob a supervisão de um tedai ou banto, até chegar a deteminada idade. Nunca os trate com privilégio algum;

- o mais importante no negócio é saber a hora de vender o estoque encalhado, liquidando-o pelo preço baixo. O pequeno prejuízo do momento evita uma perda maior no futuro. 
Seguindo os ensinamentos de Takatoshi, a família Mitsui, junto com mais 10 famílias ramificadas, manteve-se unida e conseguiu criar um dos maiores conglomerados econômico-industriais do Japão no século XX.

A vida e a saga de comerciantes como Takatoshi foi contada por Saikaku Ihara (1642-1693), o escritor mais popular daquele período (MINAMOTO, 1993). De acordo com os dados estatísticos existentes, havia, então, em Tóquio, 800 locadoras de livros, cuja leitura se tornava uma das diversões da população, graças à proliferação das terakoyas, as já mencionadas escolas primárias da época. Numa de suas obras, Ihara, por meio de uma figura por ele criada, disse que um comerciante, para ser rico, deveria tomar uma pílula chamada "chojamaru” (choja significa homem rico em japonês e maru, pílula) cujos componentes são: acordar cedo, dedicar-se aos negócios da família, fazer serão, poupar dinheiro e manter boa saúde. Na obra, ele explicou que fazer economia não significa apenas guardar dinheiro. O importante é saber investir no negócio certo na hora certa. Advertia que tomar a pílula junto com um veneno faria a pílula perder sua eficácia. O veneno, explicou, seria descuidar-se do negócio principal da família, dedicando-se a negócios secundários; levar uma vida ostentosa, muito além do seu padrão; ser fiador de alguém sem saber do que se trata; gastar dinheiro poupado em negócio aparentemente de fácil e alta lucratividade; praticar jogos de azar; exagerar nas doações e tomar empréstimo a juros altos.

Ihara, que foi comerciante até os 34 anos de idade, ensinou que para ser um bom comerciante é fundamental fazer negócio identificando a real necessidade do consumidor, mantendo a credibilidade tanto perante seus empregados quanto diante dos clientes. Por meio de suas obras e da de outros autores, largamente lidas pela população de Tóquio, bem como sob a influência de outros pensadores, como Ishida, atributos como sagacidade, trabalho duro, honestidade e credibilidade eram reconhecidos como requisitos necessários para ser um bom comerciante (DOOMON, 1996).

\section{Famílias, casas comerciais e preceitos (kakun) da época}

A família Moji continua, até hoje, como um dos principais acionistas do fabricante do molho de soja japonês Kikkoman. Dizem que o início da fabricação do molho pela família foi em tomo de 1558-1570, na região suburbana da Tóquio de hoje. Em 1824, a família, junto com outros sócios, chegou a ter 19 fábricas. Hoje, no Japão, há aproximadamente 1.600 empresas que fabricam o molho de soja, mas a marca mais famosa mundialmente é, sem dúvida, a Kikkoman. Aparentemente, o kakun da família Moji sofreu algumas modificações no decorrer do tempo. A versão mais conhecida era a de 1896, tendo sido apresentada por Kester (1991), além de diversos pesquisadores japoneses. Veja-se, a seguir, a versão de Yamamoto (2005):

1. ética em primeiro lugar. Lucro em segundo plano. Nunca esqueça isso;

2. mantenha a paz interna da família;

3. evite luxo e extravagância. Mantenha-se na virtude da frugalidade e da simplicidade;

4. não faça negócios que não estejam relacionados com a atividade principal da família;

5. o maior lucro é não sofrer prejuízo;

6. a competição é a origem do progresso, mas evite a concorrência irracional ou desnecessária;

7. cuide bem da higiene e da saúde. A refeição é só com cereais de segunda, com uma sopa. Coma o mesmo que seus empregados comem;

8. faça doações para obras públicas com a economia de seu próprio dinheiro. Entretanto, não a faça além da quantia compatível com sua posição;

9. cada membro da família deve poupar seu dinheiro, preparando-se para a hora da adversidade;

10. convoque uma reunião familiar duas vezes por ano. Na ocasião, o que deve ser priorizado e louvado é o caráter do indivíduo, não a riqueza que este acumulou. 
Pode-se notar que aqui estão expressos os pensamentos empresariais típicos da época. Hoje, a empresa continua atuante, seguindo a diretriz que sempre norteou o negócio principal da família: a fabricação do molho de soja.

Quanto à Takashima-Ya, uma das maiores redes de loja de departamentos (em 2006, liderou o mercado de lojas de departamentos, em termos de faturamento), foi fundada por Shinshichi Iida (1803-1874). Ele começou como decchi de uma casa comercial, mais tarde foi caixeiro viajante e depois, em 1831, conseguiu abrir o seu próprio estabelecimento, Takashima-Ya, vendendo roupas usadas, tecidos e panos de algodão. A base do seu negócio era a credibilidade com os clientes. O interesse dele não se limitava ao negócio no Japão; assim, participou das exposições mundiais de Barcelona e de Paris. Foi ele quem lançou no Japão o método de exposição de mercadorias em vitrine. Em 1910, a empresa participou, também, da exposição mundial de Londres, ganhando diversos prêmios.

Iida estabeleceu o kakun em quatro parágrafos, de acordo com sua filosofia do negócio, determinando que seus familiares e empregados os observassem rigorosamente (YAMAMOT O, 2005):

1. vender produtos de qualidade por preço accessível, assegurando lucro tanto para os clientes quanto para nós;

2. vender produtos à vista. Não venda a crédito com juros;

3. informar aos clientes todas as qualidades e defeitos do produto à venda, sem deixar nenhum ponto obscuro;

4. tratar todos os clientes com absoluta igualdade, sem dist inção entre ricos e pobres.

Em 1864, houve um conflito armado em Kioto (conhecido na história do Japão como Hamagurigomon no $\mathrm{Hen}$ ), entre o exército do feudo de $\mathrm{Aizu}$ - que ainda apoiava o decadente governo Tokugawa - e o exército misto dos feudos progressistas de Chōshū e Satsuma, as principais forças da oposição da época. A cidade de Kioto entrou em colapso, devido aos incêndios e ao quebra-quebra generalizado que resultaram na destruição de lojas e de depósitos de casas comerciais. A escassez de mercadorias foi sentida logo depois do conflito, mas apesar dessa oportunidade de lucros fabulosos, a Takashima-Ya sobreviveu vendendo seus produtos por preço justo, de acordo com os preceitos de Iida. Essa postura tomou-se do conhecimento de todos, granjeando admiração para a Takashima-Ya, cuja credibilidade atingiu seu auge. "A Takashima-Ya não faz negócio desonesto e mantém seus preços, mesmo diante da oportunidade de grandes lucros”: esta foi uma afirmação que ficou enraizada na lembrança de clientes e de moradores da região (YAMAMOTO, 2005).

Outra rede de lojas de departamentos de grande porte - a Daimaru, que em 2006 foi a terceira colocada em termos de fat uramento no segmento -, teve sua origem com Hikoemon Shimomura (1688-1748). O começo do negócio remonta a 1717, quando Hikoemon iniciou a venda de roupas usadas em Kioto. Como pequeno comerciante, porém, ele ajudava as pessoas pobres da redondeza. Em 1726, abriu outra loja, em Osaka. O avanço em direção a Tóquio aconteceu em 1728. Diversas outras lojas de grande porte foram abertas, seguidamente, no país inteiro.

Shimomura mostrou seu talento como homem de marketing desde cedo. Na loja de Tóquio, deu início a um serviço de empréstimo de guarda-chuvas aos clientes durante chuvas ocasionais. Na verdade, a idéia de emprestar guarda-chuva a clientes era da Echigo-Ya, da família Mitsui. Shimomura, porém, colocou o nome da Daimaru nos guarda-chuvas, utilizando-os como instrumento de propaganda da sua rede de lojas (YAMAMOT O, 2005).

O lema da Daimaru estava resumido no kakun da família, elaborado em 1736. Shimomura sempre citava e gostava das palavras deixadas por um acadêmico chinês do confucionismo, segundo o qual, quem prioriza a justiça e o dever, deixando o lucro para trás, prospera. Para Shimomura, ao se insistir no cumprimento do dever social e na fidelidade com os clientes, o lucro justo é garantido de modo natural. Contribuição social e dedicação total ao cliente são os dois pilares da política da Daimaru, ainda hoje. Em 1738, Shimomura estabeleceu um conjunto de normas e princípios de conduta. A opinião da comunidade da época era a de que a Daimaru tratava, da mesma forma, senhores samurais e donas de casa pobres, que fazia negócio absolutamente 
justo com qualquer pessoa, sem discriminação. Diziam que todos os empregados se orgulhavam de trabalhar como membros da Daimanu, que sabiam estar vendendo credibilidade aos clientes e não, simples mercadorias (T AKEMIT SU, 2003).

O verão de 1833 foi o início de prolongada crise nacional, em conseqüência de uma crise agrícola em grande escala causada por sucessivas más colheitas. Foi um verão com temperat ura extremamente baixa e sem as chuvas de que o campo precisava. O governo Tokugawa não tomava medidas adequadas para aliviar a crise que castigava severamente a população, enquanto grandes comerciantes e atravessadores especulavam com o preço do arroz, produto cujo centro logístico ficava em Osaka.

Em 1837, Öshio Heihachiro (1793-1837), samurai e servidor público dessa cidade, sensibilizado com a fome e a angústia da população, liderou, como protesto, um motim armado contra grandes estabelecimentos comerciais e residências luxuosas de atravessadores. Nesse conflito, as lojas da Daimaru foram poupadas dos ataques, pois era vista como uma rede que praticava um comércio justo e honesto (T AKEMIT SU, 2003).

Outro comerciante de sucesso foi Jihei Nakamura (1685-1757). Proveniente da região de Oomi, legou palavras que caracterizam bem o pensamento empresarial dos comerciantes da região. Em 1754, Nakamura escreveu para seu filho adotivo Soujiro (então, com 15 anos) uma carta que ficou conhecida como "Recado para Soujiro":

Quando viajar a outra região para fazer negócio, tome o máximo cuidado para que os consumidores do local sejam bem atendidos e que possam comprar e usar os nossos produtos com maior satisfação. Não pense apenas no seu interesse. Lucro ou prejuizo dependem do favor e da vontade natural do céu. Não procure uma alta margem de lucro e trate bem as pessoas de cada higarporonde você passe. Se fizer isso, você pode manter sua consciência absolutamente tranqüila e gozar de boa saúde. Sempre respeite as divindades budistas e xintoistas e pense sempre no que acabo de lhe dizer antes de viajar (YAMAMOTO, 2005).

A região de Oomi, perto de Kioto, ainda hoje é conhecida como centro de excelência na formação de grandes empresários, ao lado de Osaka. Desde o século XV, muitos empresários e comerciant es nascidos na região têm sido bem-sucedidos. Como tantos outros comerciantes, Nakamura iniciou sua carreira como caixeiro viajante. Carregando na mão suas mercadorias e uma balança, trabalhava dia e noite, percorrendo a pé todo o país. Repetia seus trajetos e conquistava credibilidade diante de clientes das mais diversas regiões. A base do seu negócio era a honestidade, o lucro modesto e a visão de longo prazo. Somente quando conquistava um número expressivo de clientes fiéis é que abria um estabelecimento fixo numa região. Como os outros caixeiros viajantes, Nakamura contribuiu para incrementar a economia do país ao exercer o papel de agente logístico. Levavam mercadorias de uma região para outra onde houvesse demanda e, na volta, procuravam produtos do local, levando-os para outra região. Sem dúvida, a visão de longo prazo o poupava de mazelas típicas do comerciante imediatista: alto lucro numa só transação, descumprimento de promessas verbais, mau atendimento pós-venda etc. (YAMAMOTO, 2005).

As atividades dos comerciantes de Oomi tinham caráter social e seus pensamentos podem ser resumidos em três conjuntos de palavras: “Bom para nós, bom para os clientes e bom para a comunidade.” O negócio bom para as três partes era o verdadeiro negócio válido para os comerciantes de Oomi e, por isso, nunca faziam negócio com alto lucro (mesmo quando podiam), em detrimento dos clientes (SUENAGA, 2000).

Outro comerciante de sucesso de Oomi, Yozaemon Tonomura nasceu em 1682, de uma família que se dedicava a atividades rurais. Aos 18 anos, Tonomura começou a vida de vendedor viajante, ganhando, pouco a pouco, a confiança dos clientes. O maior sucesso da família, porém, começou com um descendente dele, o oitavo Yozaemon, em 1822, quando este inaugurou uma loja em Kioto. O negócio da família continua hoje como Tonoyo, empresa de sociedade anônima (YAMAMOT O, 2005).

A família Tonomura deixou diversos kakuns e suas versões modificadas, parcialmente, por descendentes de Yozaemon. Um desses documentos, chamado Kokoresho, foi elaborado em 1856, quando o Japão começava a 
passar por grandes mudanças sociopolíticas, no final da era Tokugawa. Um trecho do Kokorøesho diz (SUENAGA, 2000; YAMAMOTO, 2005):

O importante é vender mercadorias pelo preço que o consumidor queira pagar com prazer. Trata-se de preço razóavel e accessivel para compradores. Se você se arrepender por ter vendido mercadorias por preço muito baixo, é bom sinal, pois os clientes devem estar contentes e vão voltar a fazer negócio com a gente. A essência do ótimo negócio é não arrepender-se depois da venda. Não se esqueça disso!

Em outro trecho observa-se o seguinte: "Para ser um bom comerciante, deve munir-se de visão de longo prazo do negócio e ter a capacidade de previsão e perspicácia sobre o futuro. Quem não tem essa capacidade, não é para ser comerciante.”

Um trecho das regras internas de Shiroki-Ya, de 1723, já citado, diz que “Independentemente do volume de compras, deve se dispensar a mesma at enção a todos os clientes, para que estes se sintam em casa.” O mesmo espírito de atendimento de excelência é defendido nos escritos da família Saburoohyooe Sugiura (Daikoku-Ya) que diz: "Quando um cliente entrar no nosso estabelecimento, devemos tratá-lo com a máxima atenção, independentemente do volume de compras" (NISHIYAMA et al, 1995).

Elaborado em 1744, o kakun da família de Nihyoue Oomiya, grande comerciante de Kioto, por seu tumo, diz categoricamente: “Os clientes são os nossos senhores e os pais da nossa vida.” (NISHIYAMA et al, 1995)

O kakun de 1745, de Chikiriya, que comercializava vestidos de monges budistas, também em Kioto, igualmente expressa alguns pensamentos interessantes: (NISHIYAMA et al, 1995)

- todos da família devem se dedicar ao negócio principal criado e mantido pelos antepassados, evitando atos levianos caract erizados de ost ent ação ou jogos de azar.;

- todos devem seguir rigorosamente todos os regramentos e orient ações baixados pelo governo;

- os comerciantes, tanto os superiores quanto os inferiores, estão todos unidos pelo mesmo destino. Os superiores devem proteger e cuidar bem dos inferiores e estes devem respeitar os superiores servindo com dedicação;

- se o chefe desta família tiver uma conduta inadequada a sua posição, o representante de todos os tedais pode e deve opinar contra, baseando-se em argumentos justos;

- se mesmo sob o justo protesto dos tedais o chefe desta família não se corrigir, deve ser destituído e forçado a aposentar-se. Seu sucessor deverá ser escolhido em consenso entre familiares e executivos da casa.

Nessa casa comercial, a classe dos tedais correspondia à dos bantōs de outras casas. Os cargos e suas denominações mudavam um pouco de casa para outra. Observamos nesse kakun, uma ênfase no negócio principal da família e a preocupação com possível falha na observância das regras estabelecidas pelo governo Os comerciantes temiam ficarem visados pelo governo e sofrerem alguma punição. O princípio da capacidade individual era rigorosamente seguido por essa família, para a qual a linhagem não era decisiva na escolha do sucessor, pois o que se buscava era a longevidade dos negócios (NISHIYAMA et al, 1995).

\section{Kakun e longevidade}

A informação sobre o kakun de diversos comerciantes da época permite que se tenha uma idéia sobre o sistema de valores e a estrutura básica da ética empresarial da classe dos comerciantes. No fundo, há uma ênfase no comportamento moral e na ética proveniente do budismo, do xintoísmo e do confucionismo. O kakun da família de Jihei Morita, fundador da farmácia datada de 1680, em Tóquio, diz (YAMAMOT O, 2005):

- a ingratidão deverá ser retribuída com o favor;

- quando tiver remorso, faça uma boa ação para afastá-lo; 
- aceite a facilidade ou a conveniência se isso for obtido com muito suor e sacrifício;

- viva com honestidade e nunca duvide de ninguém...

- você pode ser enganado, mas nunca engane ninguém;

- a união da família é a essência da riqueza e da felicidade.

A extrema honestidade, tanto na vida particular quanto na vida profissional, a especial preocupação com os outros e o interesse com a causa pública compunham o que era comum nos kakuns das casas comerciais da época. Haviatambém muitos kakuns que advertiam contra ou mesmo condenavam veementemente os jogos de azar, a bebida alcoólica e o envolvimento com amantes. De certa forma, essas casas comerciais conseguiam manter um padrão ético por meio de avaliação rígida e permanente dos seus empregados, no dia-a-dia do trabalho.

A chave de um bom negócio estava no lucro modesto. O kakun de 1843 da família Tsukada Hyouemon - a qual acumulou grande fortuna negociando algodão - enfatizava a importância de uma modesta lucratividade. De acordo com esse kakun, alto lucro, mesmo obtidb por sorte ou devido a circunstâncias favoráveis, afastaria futuros clientes, por ser algo negativo a longo prazo. O melhor negócio seria, como indicava o lema dos comerciantes de Oomi, aquele que distribuísse o lucro igualmente por todas as partes interessadas: clientes, comunidade e o próprio comerciante (YAMAMOTO, 2005). A melhor alternat iva nem sempre era aquela que proporcionasse maior resultado quant itativo financeiro no momento. O negócio, para a classe de comerciantes da época, não era simplesmente um meio para maximização da riqueza dos sócios. Era questão da própria sobrevivência do proprietário e de sua família; acima de tudo, a sua razão de ser na sociedade.

Outro ponto importante era a insistência em permanecer no negócio principal da casa. Os kakuns advertiam quanto ao perigo da diversificação. Sabiam que cada um tem sua capacidade profissional limitada, sem condições, portanto, de ampliar levianamente seu leque de atividades. Observando por outro ângulo, defendiam a idéia de que, no caso de uma crise de sobrevivência ou de identidade corporativa, quem tivesse seu negócio principal consolidado o suficiente para enfrentar as adversidades, passada a crise poderia a ele retornar. A já mencionada Kongo Gumi, por exemplo, entrou em crise por compet ir com empreiteiras de grande porte na construção de prédios e obras de concreto com varas de ferro. A especialidade dela é a reforma e a construção de templos de madeira. A empresa se encontra num processo de reabilitação, voltando a sua origem. Foi, portanto, um caso mal-sucedido de diversificação, contra a qual pregava o kakun da casa.

O amparo moral e ético foi fundamental para a classe de comerciantes da época manter suas atividades com dignidade e consciência quanto ao seu papel na sociedade. Reside aqui uma semelhança com o que Max Weber (1864-1922) analisou ao usar a palavra “Benuf”, que significa "vocação". Segundo ele, nos países onde o protestantismo era predominante existia uma palavra que correspondia a esse conceito. Weber afirmava que a maior influência da reforma religiosa de Martinho Lutero (1483-1546) fora atribuir um caráter moral à ocupação laboral popular (WEBER, 1920). A proposição de Lutero de que cumprir fielmente com as obrigações no trabalho, diariamente, coloca a pessoa, de um ponto de vista moral e religioso, no patamar mais elevado, apresenta muitas semelhanças com o pensamento central da escola Shingaku, de Baigan, que proporcionava autoconfiança moral e ética aos comerciantes japoneses.

Neste artigo, analisamos somente as casas comerciais do Japão, embora também haja muitos fabricantes centenários naquele país. Nomura Susumu, já aqui referenciado, enfatiza que a tradição japonesa se encontra mais no segmento de atividades manufatureiras. Aproximadamente, 45 mil entre 100 mil empresas com mais de 100 anos de vida têm sua origem nesse segmento e, hoje, elas são modernos fabricantes de máquinas, equipamentos etc. Um dos exemplos é a Nabeya, empresa fundada há 450 anos como fabricante de panelas (nabe em japonês) de aço, que hoje fornece autopeças para montadoras. O kakun dessa empresa é composto de três princípios: sistema de bantō na gestão (uso de gerente geral responsável por toda a gestão do negócio), não se meter em política e manter-se no negócio principal da família (NHK, 2007). A técnica de confeccionar panelas continua na fabricação de autopeças em dois pontos: com a técnica de fundição e a de processamento e beneficiamento de metais. A empresa continua na linha do negócio da família. 
Ao pôr em prática seus kakuns, as corporações japonesas sobreviveram e se tomaram centenárias, numa trajetória sem fatores históricos excepcionais que lhes facilitassem o funcionamento. Pelo contrário, foram inúmeras as mudanças radicais de caráter sociopolítico em diversos períodos conturbados. Não é por acaso que também na Alemanha haja registro de inúmeras empresas centenárias. Tanto lá quanto no Japão, a situação sociopolítica que cercava essas empresas não era pacífica, tampouco propícia à manutenção dos negócios. Entretanto, havia algo mais do que simplesmente sorte.

\section{Para concluir}

Este artigo objetivou analisar a longevidade das casas comerciais do Japão e de outras corporações tradicionais daquele país, com foco no kakun. Nos dias de hoje, esse conjunto de preceitos e normas ainda pode ser encontrado afixado nas paredes de escritórios de centenárias empresas japonesas, nas quais, em diversas ocasiões, se não todas as manhãs, é lembrado por todos os seus membros.

Conforme já explicitado, o kakun é a manifestação resumida do espírito empresarial japonês, tendo possibilitado longa vida a essas corporações por reunir pensamentos éticos e fundamentais para a prática de bons negócios. Nesse sentido, o kakun cumpriu e ainda cumpre o papel que lhe foi atribuído pelos fundadores de antigas casas comerciais e corporações. Curiosamente, essa gênese de bons negócios não mudou muito, mesmo com as mudanças radicais trazidas com o passar do tempo. Além disso, muito do aqui se explicitou pode ser identificado nos estudos sobre cultura organizacional. Veja-se, por exemplo, que Aktouf (1994) apresenta, entre as características viabilizadoras de uma identidade compartilhada, a quase total ausência de sinais de distanciamento ou de diferença de status, a inexistência de privilégios exclusivos e a defesa de um comportamento justo e igualitário por parte de dirigentes.

Do ponto de vista da mercadologia moderna, os princípios sob a forma de kakun, seguidos à risca por várias gerações nas centenárias corporações japonesas, não são um referencial obsoleto que engesse a economia pelo paternalismo, como muitos apregoam (DUALIBI, 2007). Ao contrário, analisando-se minuciosamente cada uma de suas proposições, as quais conformam um padrão cultural alicerçado na ética, podemos afirmar que no kakun está a essência da verdadeira mercadologia moderna. Isso acontece por uma razão: por defender que as corporações sempre se coloquem no lugar dos clientes (como observamos, algumas casas comerciais chegaram a afirmar que estes seriam "Deus para elas") e que contribuam para a sociedade (através, por exemplo, de doações para obras públicas). No dias de hoje, isso significa at entar para a satisfação do cliente e para o papel social das empresas

Os comerciantes da época, de certa forma, ant eciparam esses conceitos modernos, incluindo também a gestão por competência e por resultados. Eles igualmente vivenciaram o trabalho em equipe, valores, carreira, competitividade, visão de longo prazo, investimentos e tantos outros tópicos que a leitura deste texto permite identificar. A força motriz das atividades era a religiosidade associada a valores morais representados pela honestidade, pelo comprometimento e pelo caráter, entre outros. Modernamente se diria: a força motriz das centenárias corporações japonesas tem um grande componente de espiritualidade, entendida esta como bem intangível.

Se no estudo aqui apresentado nos debruçamos sobre a era $E d o$ para buscar as raízes da longevidade das empresas japonesas, privilegiando a ética, seria interessante que outras pesquisas estabelecessem, por exemplo, o que deve ser culturalmente levado em conta numa negociação entre Brasil e Japão. Fica aqui a proposta. 


\section{Referências}

AKTOUF, Omar. O simbolismo e a cultura da empresa: dos arcabouços conceituais às lições empíricas. In: CHANLAT, JeanFrançois (Org.). O indivíduo na organização - dimensões esquecidas. São Paulo: Atlas, 1994.v .II.

CURADO, Isabela. Pesquisa historiográfica em administração: uma proposta metodológica. In: ENCONTRO NACIONAL DA ASSOCIAÇÃO NACIONAL DOS PROGRAMAS DE PÓS-GRADUAÇÃO EM ADMINISTRAÇÃO, 25., 2001. Campinas. Anais... Campinas: Anpad, 2001.

DOOMON, Fuyuji. Edo shouninno keizaigaku (Economia dos comerciantes de Edo.). Tóquio: Maruzen, 1996.

DUAILIBI, Júlia. Atrás da riqueza. Veja, São Paulo, ano 40, n.49, p.140, 12 dez 2007.

FUNABASHI, Haruo. Shinnihon eidaigura (Nov a prosperidade de negócios duradouros no Japão). Tóquio: Nikkei BP Shuppan, 2003.

KESTERW. Carl. Japanese takeovers. Massachusetts: Harv ard Business School Press, 1991.

KOJIMA, Keizo. Edo no sangyou Renai ssance (Renascença Industrial de Edo). Tóquio: Chuo Kooronsha, 1989.

KUWATA, Tadachika. Bushino kakun (Kakun de samurais).Tóquio: Koodansha, 2003.

MINAMOTO, Ryœn. Tokugawa shisou shoushi (Breve história de pensamentos da era Tokugawa.) Tóquio: Chuo Kooronsha, 1993.

NHK, Nihon Housou Kyokai. Chooju kigyou taikoku Nippon (Japão de empresas duradouras) de 18 jun. 2007.

NISHIYAMA, Matsunosuke et al. Edojidaino joushiki hijoushiki (Senso comum e falta de senso comum da era Edo). Tóquio: PHP Kenkyujo, 1995.

NOMURA, Susumu. Sennen hataraitekimashita (Trabalhando mais de mil anos). Tóquio: Kadokawa Shoten, 2006.

OGl, Shinzo et al. Zusetsu Ooedo (Grande Edo: suas interpretações). Tóquio: Jitsugyouno Nipponsha, 1997.

OISHI, Shinzaburo. Edo jidai (Era Edo).Tóquio: Chuo Kooronsha, 1995.

REGO, Armênio et al. Espiritualidade nas organizações e empenhamento organizacional: um estudo empírico. Portugal: Univ ersidade de Aveiro, 2005. Disponível em <http://www.egi.ua.pt>. Acesso em: 14 ago. 2006.

SEBRAE. Boletim fatores condicionantes e taxa de mortalidade no Brasil. Brasil, 2004.

SUENAGA, Kunitoshi. Oomi shounin (Comerciantes de Oomi).Tóquio: Chuo Kooron Shinsha, 2000.

TAKAMURA, Naosuke. Kaishano tanjou (Nascimento de empresas). Tóquio: Yoshikawa Koobunkan, 1996.

TAKEMITSU, Makoto. Osaka shounin (Comerciantes de Osaka). Tóquio: Chikuma Shobo, 2003.

TAKEUCHI, Yasuo. Keizai rinrigakuno susume (Conv ite àética econômica). Tóquio: Chuo Kooronsha, 1994.

VERGARA, Sylv ia Constant. Métodos de pesquisa em administração. 2.ed. São Paulo: Atlas, 2006.

WEBER Max. Die protestantische ethik und der „Geist» des kapitalismus (1920). (tradução em japonês) Tóquio: Iwanami Shoten, 1994.

YAMAMOTO, Shinkou. Shoukano kakun (Kakun de casas comerciais).Tóquio: Seishun Shuppansha, 2005.

YASUOKA, Shigeaki. Zaibatsuno keieishi (História administrativ a de grandes grupos empresariais japoneses). Tóquio: Shakai Shisousha, 1993. 